\title{
Adapting the Mit Stirling Engine Project at the UNIVERSITY OF IDAHO, A LAND GRANT INSTITUTION
}

\author{
Nathaniel B. Allen, J. Matthew Cunnington, Levi J. Westra, Michael K. Klein, \\ Edwin M. Odom, and R. E. Smelser \\ University of Idaho \\ Mechanical Engineering \\ Moscow, ID 83844-0902
}

\begin{abstract}
Retention of students after completion of the sophomore year in Mechanical Engineering is a problem. Students who remain often display low enthusiasm which is evident in class and on school work. Our goal is to introduce an engineering project in the sophomore year that generates a high level of student interest and aids student retention. To address similar issues, MIT includes the assembly and analysis of a Stirling engine by their sophomore students. Our challenge is to adapt the MIT Stirling engine project into the curriculum of a land grant university with a different fee structure. The Idaho Engineering Works, a group of mechanical engineering graduate students, modified the MIT Stirling engine to allow fabrication in the department machine shop. We introduced the fabrication and assembly project into the Sophomore Laboratory course and designed new laboratory exercises around the Stirling engine. The first iteration of the Stirling engine project was in the spring of 2001. Student response was very positive.
\end{abstract}

\section{Introduction}

The Mechanical Engineering Department at the University of Idaho is similar to other departments in seeking ways to improve recruitment and retention as well as ideas that improve the educational experience for our students. The premier issue of "Mechanical Engineering Design" magazine included an article that described how MIT students fabricate and assemble a miniature Stirling engine. ${ }^{1}$ The article reviewed the educational objectives of the project. These included assembly, designed in tolerances, concepts of power and energy transfer, analysis of engine power output, and efficiency. Additionally, we reviewed nearly 300 student-developed web pages on the project. $^{2}$ Our conclusion was that this project captured the interest and imagination of the MIT students.

We decided to incorporate a similar experience into our curriculum. Figure 1 shows the present UI Stirling engine design and Figure 2 displays a labeled cut-away solid model. The critical dimensions of our design are equivalent to the MIT design. However, we made changes based on material availability, manufacturability, and improved aesthetics. 


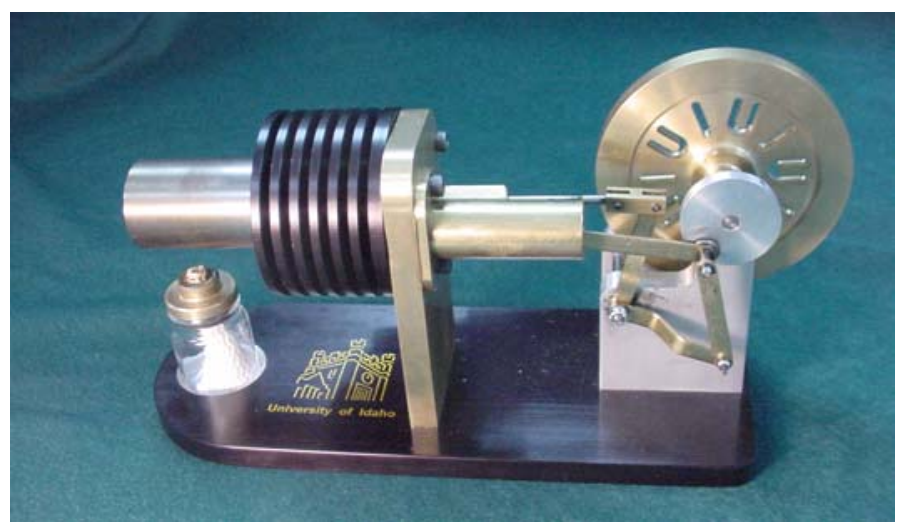

Figure 1. The University of Idaho Stirling Engine.

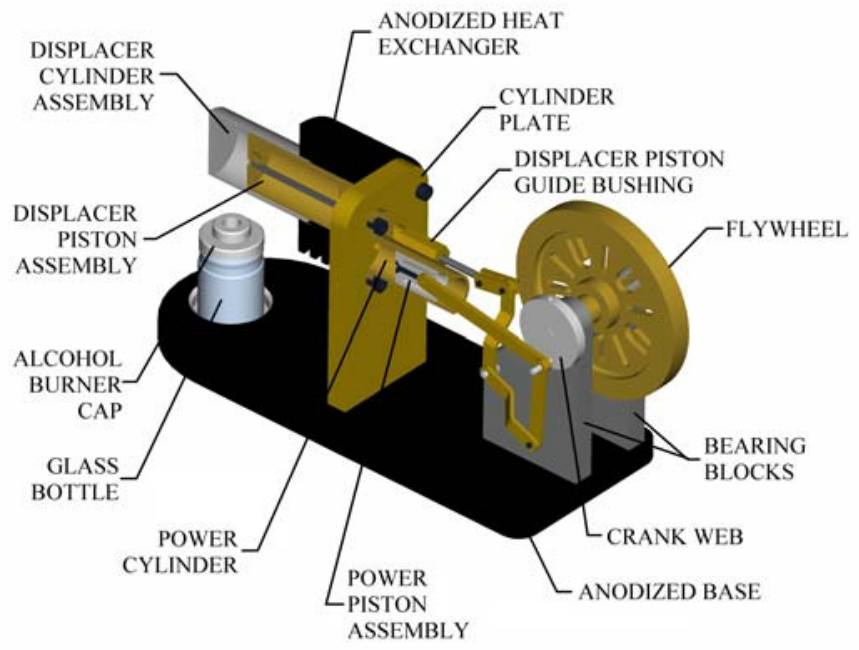

Figure 2. Labeled cut-away solid model of the UI Stirling Engine.

For this project to be incorporated into our curriculum several obstacles needed to be overcome. Obstacles included identifying and developing the educational objectives for this project, reducing the Stirling engine cost to fit within the university's fee structure, and identifying an existing course in which to include this project.

We incorporated this project into our curriculum in our Sophomore Laboratory. This is the first of a three-course laboratory sequence that culminates in a capstone laboratory project. Our Sophomore Laboratory course focuses on hands-on experiments. Students manually take data but reduce and analyze the data using a computer. To be appropriate for inclusion in this course, we developed a number of post engine assembly experiments. The Stirling engine project development proceeded by addressing the financial considerations, the fabrication experience, and the analytical and laboratory course considerations. 


\section{Financial Considerations}

Financial considerations for many projects might not be mentioned at all or be only briefly discussed. However, a good idea must be economically feasible. For the Stirling engine project, we are constrained by the $\$ 50$ fee that we assess our students for laboratory courses. If we make fees too high, we discourage students from participation in our curriculum.

We began this project by contacting the MIT faculty who developed the project to find the vendors who supply the basic Stirling engine kit and two castings, the engine base and the flywheel, as well as a set of plans for the engine. We ordered a kit ${ }^{3}$ for $\$ 110.00$ to build our prototype but decided to make the engine base from sheet aluminum and the flywheel from brass round stock. The kit assembled easily, and the engine ran with only minor difficulties in the engine timing. We explored several different materials and geometries to develop an engine with aesthetics that would separate the UI design from the MIT design. As well as the kit worked mechanically, the economics would not work.

To meet the financial constraint, we modified the engine kit and established the price for the raw materials. Our master machinist and the members of the Idaho Engineering Works (IEW) fabricated the engine kits in the department machine shop. One of the responsibilities of this group of graduate students is to assist the department in teaching the capstone design course to our seniors. This requires that the IEW members be trained in machine shop procedures. One way to gain mastery of these procedures is to fabricate components; in this case, components of the Stirling engine kit. This simplified the cost concern to finding the lowest costs of raw materials. Our total external cost of materials for a kit is $\$ 34.36$ based upon the individual component costs, Table 1. The complete UI Stirling Engine kit is shown in Figure 3.

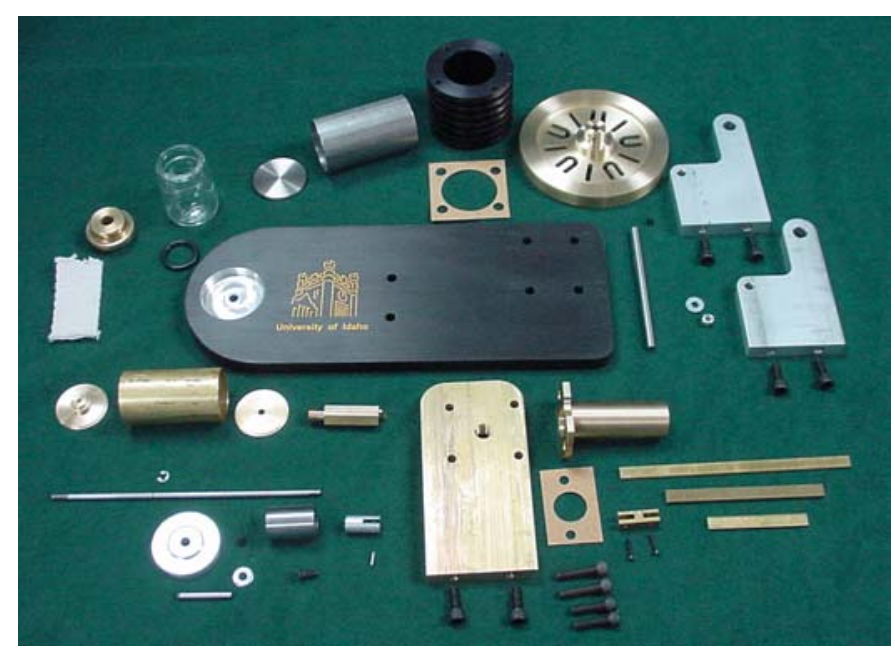

Figure 3. UI Stirling Engine kit. 
Table 1. Material Costs for one Stirling Engine.

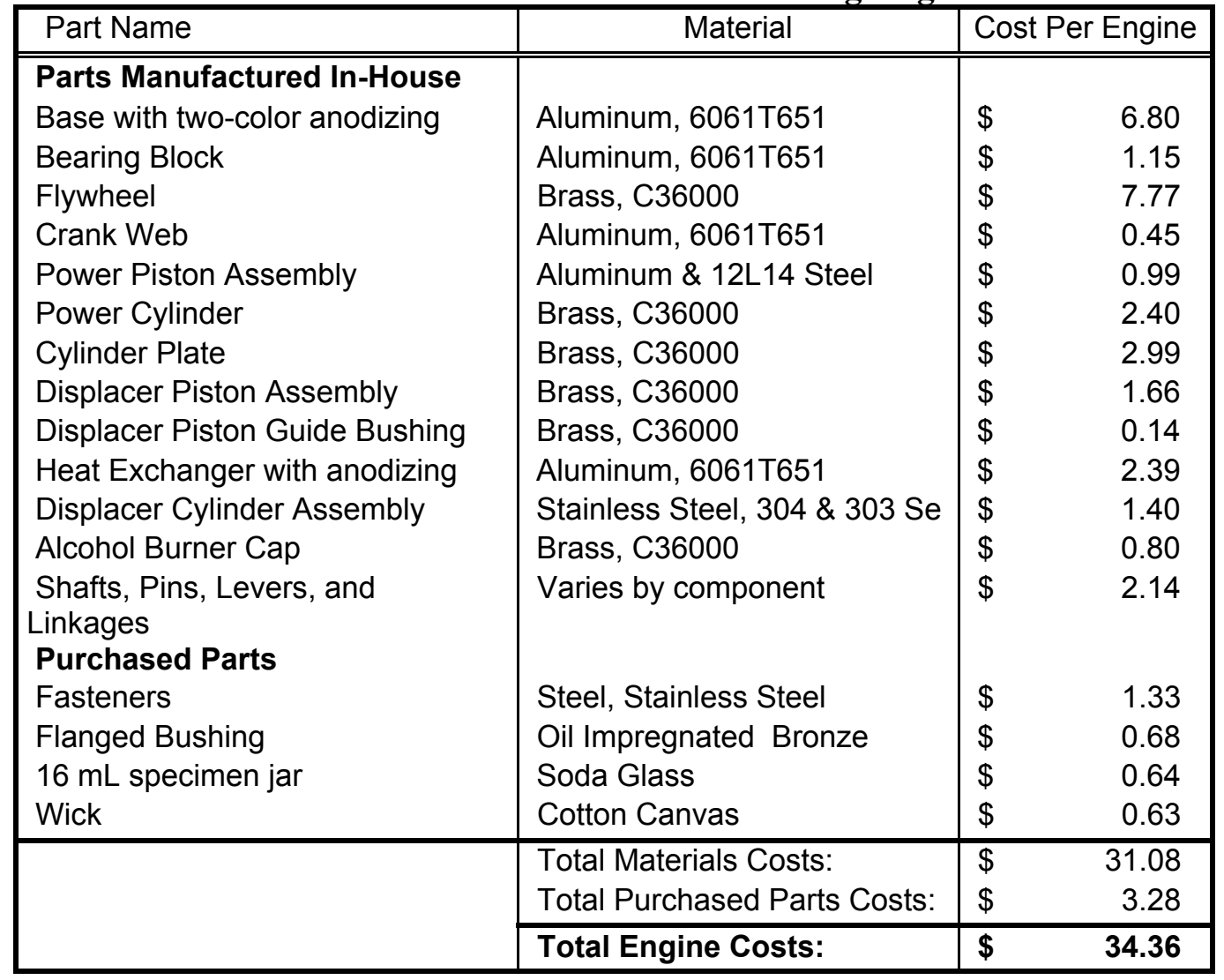

We continue to look for ways to reduce the overall cost of the engine. A redesign of the brass flywheel reduces material cost by $\$ 3.46$ per engine and decreases machining time. Another example is the redesign of the power cylinder as a two-piece assembly to reduce cost and machining time. Fabrication difficulties contributed to a decision to return to the more expensive but significantly more robust original single-piece design.

\section{Student Machine Shop Experience}

Over a two-week or three-week period, students spend the regular laboratory session in the department machine shop. This time is used to fabricate simple components, conclude fabrication of more complex parts, perform fit and finish work on the engine components, assemble, and test the completed engine. Many students perform additional fit and finish work outside the normal laboratory times to enhance the appearance of their engines.

The machine shop time is also used to introduce the students to basic shop processes and machine tools. These include manual milling machines, manual lathes, CNC mills, drill presses, belt sanders, and metal band saws. A series of simple operations exposes each of the students to these tools. A several jigs and fixtures facilitate mass-production of student manufactured parts that have good dimensional accuracy and complete interchangeability. These fabrication tools subtly introduce principles of jig and fixture design. Assembly methods are also introduced through this project. These operations are described in the following paragraphs. 


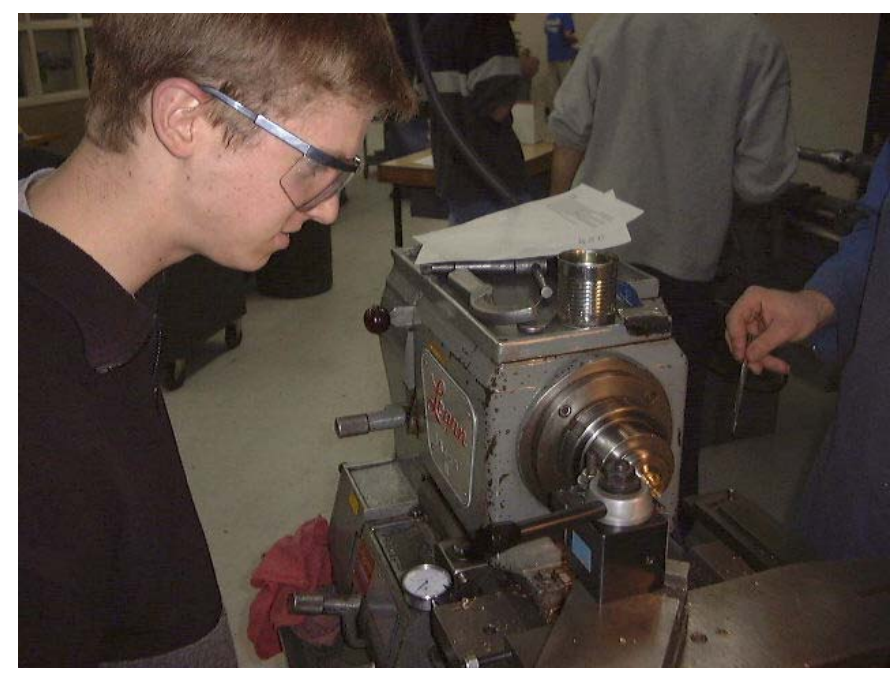

Figure 4. Student cutting O-ring groove in alcohol burner cap on a manual lathe.

Manual Milling Machines - Because the manual milling machine is a common and versatile machine tool, students perform several operations on this machine. Students conduct milling, drilling and slot-cutting operations on the gudgeon block. Later, additional drilling and counterboring operations are performed under the supervision of the master machinist or a graduate student mentor.

Manual Lathes - Four operations were performed exclusively on manual lathes and additional cleanup and finish work was performed on a manual lathe and manual mini-lathe. Students use the lathe for cutting chamfers, turning a diameter, cutting an O-ring groove, drilling, die-cutting external threads, and assembling close-fit components. Figure 4 shows a sophomore cutting the O-ring groove in his alcohol burner cap.

Drill Presses - Students use three drill presses to drill a total of twelve holes in six parts. Drill jigs, designed to locate each hole on the component, simplified fabrication of each part. The design of the jigs also required students to pay close attention to the cleanliness of the part and the jig. A few small metal chips could interfere with a proper fit between the part and the jig, thus causing a tolerance stack-up problem.

Band Saws - Several of the small components were cut either from rectangular bar stock or small diameter rods. These cuts were made on a vertical band saw or a horizontal falling band saw. This introduced students to these tools and required them to become familiar with marking material lengths. It also introduced the concept of a saw kerf or cutting allowance.

Belt Sanders - Because a band saw does not leave a finished cut edge, a belt sander was used to remove the rough ends of several of the linkage members. A sanding jig allowed students to create a fixed radius on the ends of the links; thus smoothing the appearance of the linkage members and removing potentially sharp burrs left by the cutting operation. 


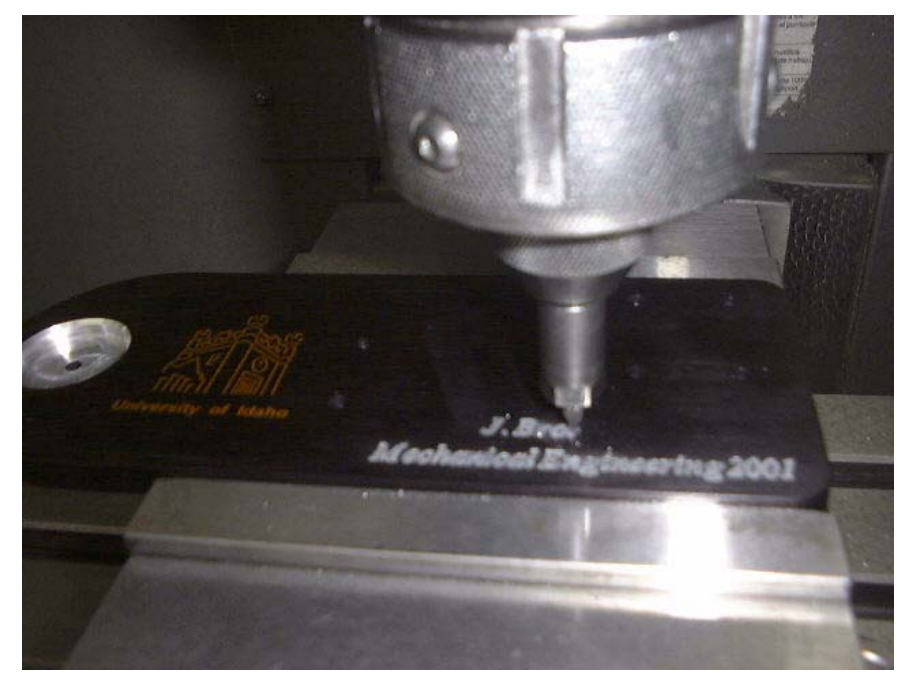

Figure 5. CNC engraving a student's engine base plate.

CNC Milling Machines - A CNC Milling Machine was used to shape several of the engine components. Because the major components were made ahead of time, the students were not able to observe most of the CNC milling operations. To demonstrate some of the machine's capabilities and to personalize each students' engines, each student's name and the line "Mechanical Engineering 2001" was engraved on each engine base, Figure 5.

Assembly and Fastening - To demonstrate assembly methods other than threaded fasteners, two sub-assemblies are made; one using a cold press fit, the other using a two-stage thermal press fit. The students use a machine vise to cold press the power cylinder and power cylinder flange together. To obtain the necessary clearance to assemble the parts, the displacer cylinder is heated and displacer cylinder end plug is then pressed into the cylinder. The displacer exchanger is also heated, and the displacer cylinder, with end plug, is pressed into it. Other components are held in place by pin joints or threaded fasteners and tapped holes or hex nuts.

Fit and Finish - Throughout the laboratory periods, we encourage students to create an excellent finish on the engine components. The students are also encouraged to obtain their own finishing supplies and to do further finish work outside of class. With the exception of profiled surfaces, the students receive the components in a mill finish condition. Although there is minimal scale on brass and aluminum, these materials do form an oxide layer that must be removed to create a highly polished surface. Dry sanding, wet sanding, and buffing are used to polish the unfinished visible components. In some instances, the stainless steel surfaces are bead blasted to create an attractive silver matte finish. 


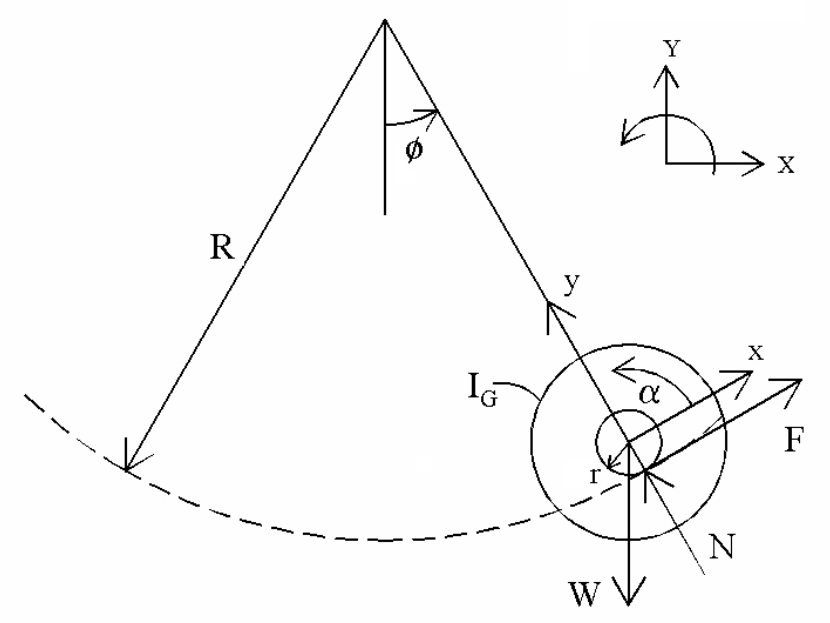

Figure 6. Diagram of rolling wheel pendulum.

\section{The Experimental Experience}

The assembled Stirling engine provides a number of opportunities for learning. In the Sophomore Laboratory course, our focus is on experimental and experiential learning. The Stirling engine provides opportunities for the measurement of the polar mass moment of inertia of the flywheel, roll down tests, spin up tests, fuel burn rate tests, and engine cool down tests. The following sections present the background and experimental details for some of these tests.

\section{Polar Mass Moment of Inertia}

We begin our Stirling engine experiments with the measurement of the polar mass moment of inertia of the flywheel. Our experimental method for measuring this is a variation of Galileo's test of rolling a cylinder down an inclined plane. This allowed Galileo to slow the free falling motion sufficiently to allow for time measurements with the instruments of that period. Since our experiment is conducted at the sophomore level and we seek student involvement during the experiment, we employ Galileo's approach to slow down the action so that the student can participate in the experiment. Our approach follows a method described by Den Hartog ${ }^{4}$ which uses a rolling wheel pendulum, Figure 6 . The goal of the analysis is a model to predict the motion of the wheel rolling on an axle along a curve of fixed radius.

In Figure 6, a local cartesian coordinate system is defined to pass through the center of the wheel. The $x$-axis is oriented tangent to the curve of radius $R$ and the $y$-axis forms a right-hand coordinate system with the $x$-axis. The force acting on the wheel is the weight, $W$. This can be resolved into orthogonal components along the local cartesian coordinates. $N$ is the normal force acting in the positive $y$-direction, and $F$ is the frictional force acting opposite to the direction of the rolling motion. The wheel with a mass moment of inertia $I_{G}$ is carried on an axle of radius $r$. The range of motion of the wheel is defined by the included angle $2 \phi$. $\phi$ is measured positive to the right of a vertical line. The angle $\alpha$ describes the rotation of the axle from the local $x$-axis at the initial position. 
From considerations of continuity for angles, the following relationship is developed.

$$
(R-r) \cdot \phi=-r \cdot \alpha \quad \text { and } \quad \ddot{\alpha}=-\frac{(R-r)}{r} \cdot \ddot{\phi}
$$

Similarly for translation,

$$
x=(R-r) \cdot \phi \quad \text { and } \quad \ddot{x}=(R-r) \cdot \ddot{\phi}
$$

Now considering Newton's Law yields

$$
\begin{gathered}
\sum F_{y} \rightarrow N \cdot \cos (\phi)=m \cdot \ddot{y}=0 \\
\sum F_{x} \rightarrow-W \cdot \sin (\phi)+F=m \cdot \ddot{x} \\
\sum M \rightarrow F \cdot r=I_{G} \cdot \ddot{\alpha}
\end{gathered}
$$

Using (1), (2), and (5), and assuming for small angles $\phi$ that $\sin \phi=\phi$, the differential equation for the motion of the rolling wheel pendulum is

$$
\ddot{\phi}+\frac{r^{2} \cdot m \cdot g}{\left(I_{G}+m \cdot r^{2}\right) \cdot(R-r)} \cdot \phi=0
$$

The solution to this differential equation leads to the natural frequency

$$
\omega=\left[\frac{m \cdot g \cdot r^{2}}{(R-r) \cdot\left(I_{G}+m \cdot r^{2}\right)}\right]^{1 / 2}
$$

Using this result, it is straightforward to develop an experiment to measure the polar mass moment of inertia of the brass flywheel of the Stirling engine. Figure 7 shows the test fixture developed for this experiment.

The two curved tracks of the fixture have a constant radius of $R$. A spacer with a dowel pin pressed through it holds a constant spacing between the two curved tracks. The modular design makes the fixture simple to fabricate. Multiple fixtures and bushings allow the effects of flywheel radius and thickness, axle radius, and track radius to be explored. The flywheel and axle are manually positioned near the top of the curve and then released. The period of the motion, $1 / f$, is measured with a stopwatch, and the frequency, $\omega$, is calculated from 


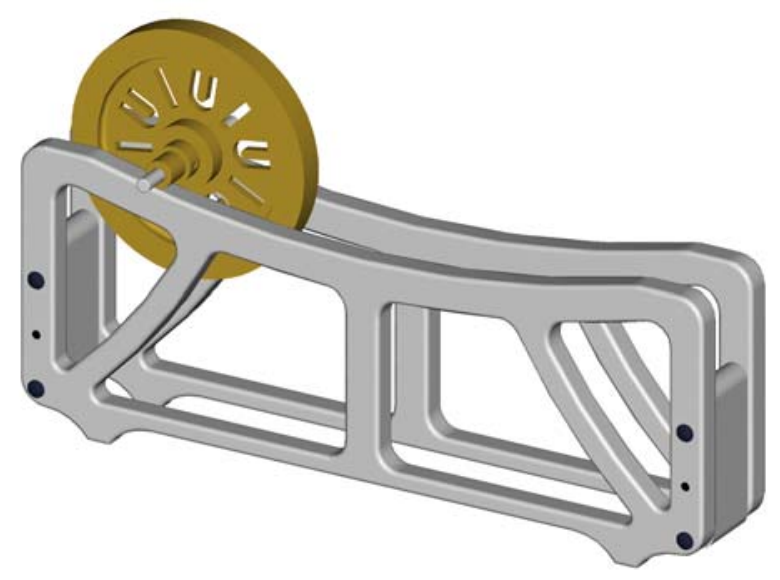

Figure 7. Solid model of fixture to experimentally determine the polar mass moment of inertia.

$$
\omega=2 \cdot \pi \cdot f
$$

The results of this experiment can be compared to a calculation of the polar mass moment of inertia using measured dimensions of the flywheel and handbook values of the density of brass. Further experiments can be performed with flywheels of different radii and thickness to aid the students' understanding of mass moment of inertia.

Table 2. Results from Mass Moment of Inertia experiment.

\begin{tabular}{|c|c|c|c|c|c|}
\hline $\begin{array}{l}\text { Flywheel } \\
\text { assembly } \\
\text { volume (in }{ }^{3} \text { ) }\end{array}$ & $\begin{array}{l}\text { Assembly } \\
\text { Mass }\left(\mathrm{lb}_{\mathrm{m}}\right)\end{array}$ & $\begin{array}{l}\text { Density } \\
\left(\mathrm{lb}_{\mathrm{m}} / \mathrm{in}^{3}\right)\end{array}$ & $\begin{array}{c}\text { MMOI (Pro/E) } \\
\left(\mathrm{lb}_{\mathrm{m}}-\mathrm{in}^{2}\right)\end{array}$ & $\begin{array}{c}\text { MMOI } \\
\text { (Experimental) } \\
\left(\mathrm{lb}_{\mathrm{m}}-\mathrm{in}^{2}\right)\end{array}$ & $\%$ difference \\
\hline 2.28 & 0.719 & 0.3154 & 1.0308 & 1.1118 & 7.86 \\
\hline
\end{tabular}

Table 2 presents the necessary data to experimentally determine the polar mass moment of inertia using Equation 7. The results indicate that this method provides a reasonable estimate of the polar mass moment of inertia.

\section{Engine Performance}

The students take great pride in the workmanship that produces their engine. There is a great "bragging right" corresponding to ownership of the fastest engine. To capitalize on the learning opportunities that this competitive spirit presents, the experimental fixture shown in Figure 8 was developed to quickly and simply measure engine speed, temperature, and fuel consumption. An infrared temperature sensor, shown on the left, non-invasively senses the temperature on the hotend of the displacer cylinder and generates a voltage proportional to Fahrenheit temperature that can be read on a hand-held digital multimeter. The infrared "eye" shown on the right counts the passage of a mark on the flywheel, in this case a small patch of Velcro ${ }^{\circledR}$ glued to the flywheel rim. The voltage signal is processed using a frequency counter, and the frequency is recorded either by hand. This instrumentation allows each engine to be tested under similar conditions and does not affect the appearance of the engine as affixing a thermocouple to the engine would. 


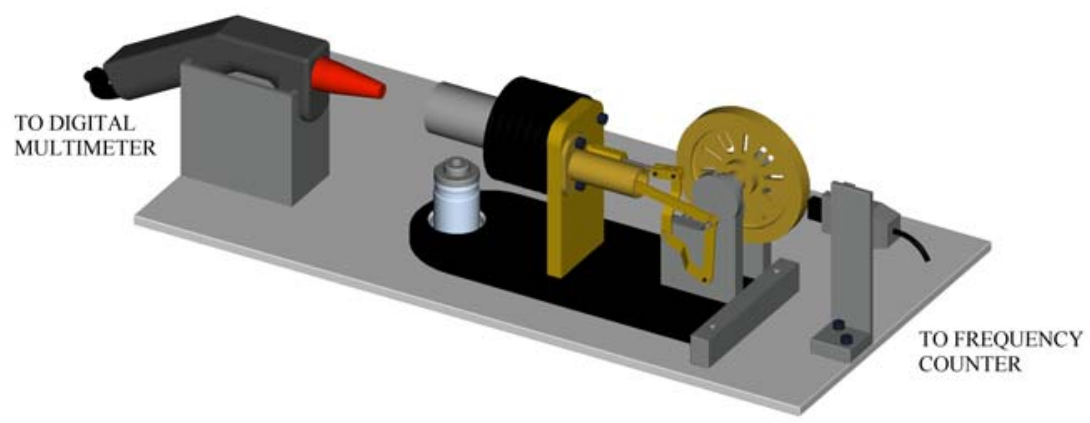

Figure 8. Apparatus for flywheel speed and displacer cylinder temperature measurements.

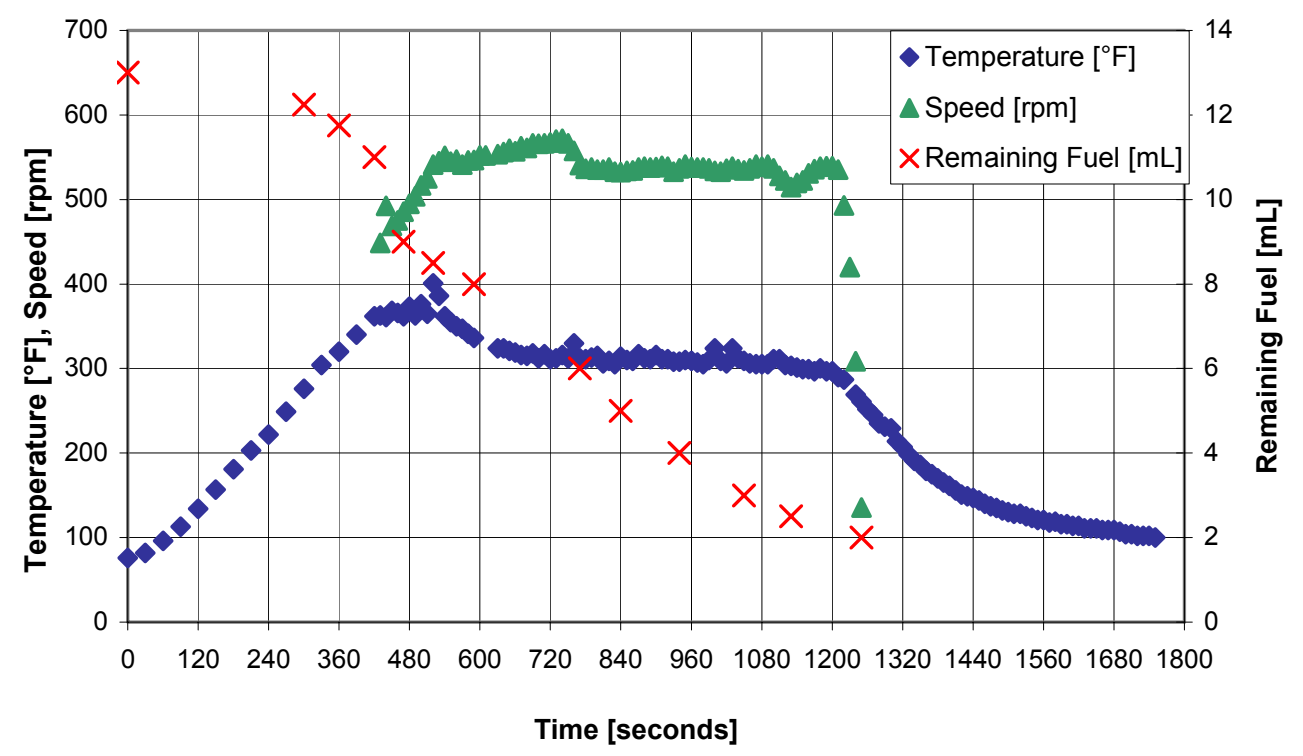

Figure 9. Sample fuel burn test and engine cooling data.

Figure 9 shows typical data from a fuel burn test. The abscissa gives time in seconds. The lefthand ordinate presents the displacer cylinder hot-end temperature in ${ }^{\circ} \mathrm{F}$ and the flywheel speed in revolutions per minute. These quantities have the same order of magnitude, and separate scales are not necessary. On the right-hand ordinate, the quantity of fuel remaining in the bottle is given in $m L$.

The first region of Figure 9 is the engine warm-up period. Temperature data is recorded in 30 second intervals, and fuel consumption is recorded intermittently. When the displacer cylinder hot-end reaches approximately $375^{\circ} \mathrm{F}$, the engine is hot enough to run, and the flywheel is given a small initial velocity. This is the second section of the plot. After the engine is started, 


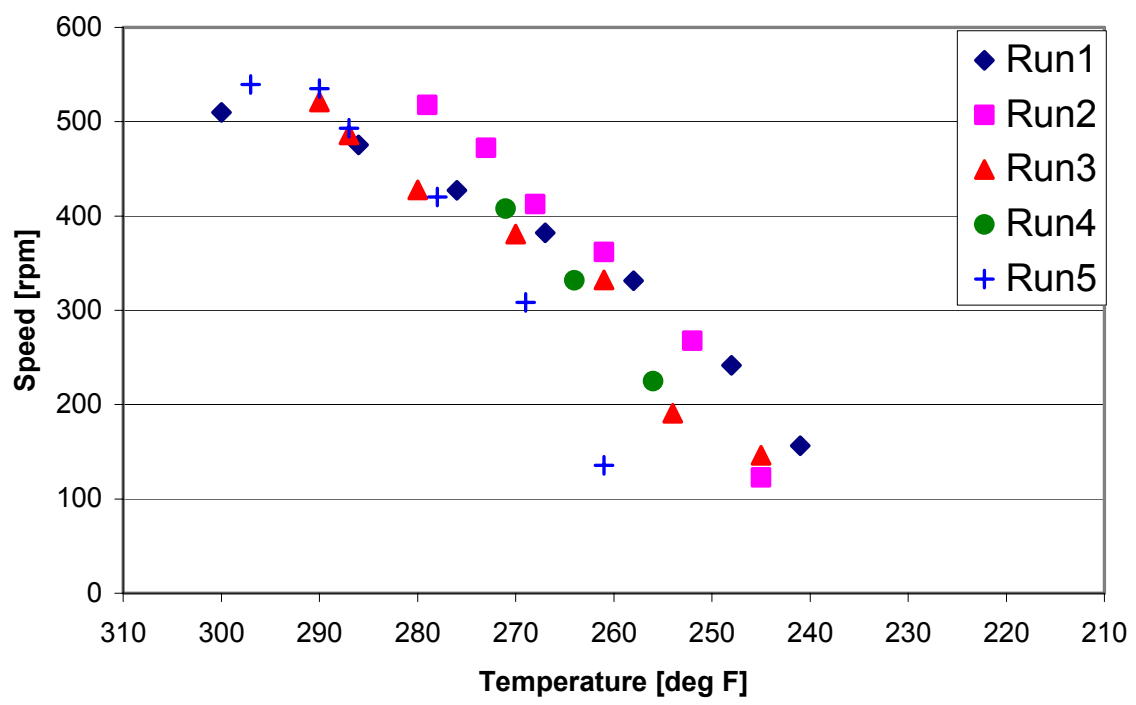

Figure 10. Coast down speed as a function of displacer cylinder hot-end temperature.

temperature and flywheel speed data is recorded in ten second intervals. The flywheel runs at an almost constant speed. After a brief transient, the displacer cylinder temperature settles to about $300^{\circ} \mathrm{F}$. The flywheel speed has a slightly longer transient and reaches a constant speed of approximately $540 \mathrm{rpm}$. The third region is very short - about 30 to 50 seconds. This is the time between flame burnout and when the flywheel stops turning. The fourth region is the engine cooling curve. Here, the displacer cylinder cools toward ambient temperature.

The cause of the peak in the flywheel speed curve is not intuitively obvious from the remaining fuel or temperature data. During the experiments, the flame characteristics shift dramatically. Before the engine is running, the flame is typically quiescent. Then flame size grows significantly. As the system progresses into steady-state operation and additional fuel is consumed, the flame again becomes quiescent. The flame was extinguished with approximately $2 \mathrm{~mL}$ of alcohol remaining in the bottle to avoid end-effects on the wick performance. We ask students to observe the flame as they are taking data and comment on the flame characteristics. Students are also asked to suggest ways to determine the effects flame characteristics have on fuel consumption, energy transfer to the displacer cylinder, and engine performance.

The fuel burn tests require a significant amount of time. A complete test may require up to 30 minutes for engine warm-up, transient run time, steady-state run time, coast down, and cool down. This does not include experimental setup or troubleshooting nor does it include the time necessary to resolve procedural errors. The logistics of performing such a lengthy experiment with 60 to 70 students makes this experiment impractical.

An abbreviated version of this experiment can be performed in approximately 10 minutes, including setup time. In the truncated experiment, the student preheats his or her engine to bring it to operating temperature before placing the engine in the experimental apparatus shown in 
Figure 8. The alcohol bottle assembly is weighed to determine the mass of fuel at the beginning of the experiment, and the engine is run long enough to obtain a steady-state speed and temperature. The flame is extinguished, and coast down and cool down measurements are made.

Figure 10 presents engine speed as a function of displacer cylinder hot-end temperature. The engine was allowed to reach steady-state operation, then the flame was extinguished and the engine allowed to coast to a stop. The temperature values on the $x$-axis are displayed in reverse order to present the intuitive direction of decreasing engine speed and order the temperature data with the time axis. Data was taken at ten-second intervals, but for clarity, the time axis is not displayed. Engine flywheel speed was plotted on the ordinate in units of revolutions per minute.

A comparison of Figures 9 and 10 shows students the importance of appropriate data collection intervals and proper plot scaling. In Figure 9, there is such a quantity of data that the engine coast down is obscured because of its brevity. Figure 10 reveals a very clear trend simply by changing the presentation of the data. Run 5 in Figure 10 was extracted from the data presented in Figure 9. Students are asked to generate similar plots with their own engine. They must explain the regions of their plot and comment on differences between Figures 9 and 10 and their own plots. The tight grouping and linearity of the five data sets in Figure 10 show that the engine losses are linear. This indicates that frictional forces dominate the coast down cycle.

\section{Conclusions}

This project was first implemented at the University of Idaho in the Spring 2001 semester. The student feedback on this project has been overwhelmingly positive - both from those students in the class and from students who happen to observe the engine during fabrication or operation. Although the initial cost of this project may seem daunting, we have shown that through creative use of internally available resources, this project is economically feasible for institutions with various fee structures. By fabricating the engine kits in-house, we generate an excellent machine shop training context for graduate students who desire to improve their shop process skills.

This project captures the imagination of the students, while introducing them to many critical mechanical engineering concepts and skills including design intent, fits and tolerances, fabrication procedures, machine shop practices and processes, and systems analysis. Analytical and experimental skills are developed through combined exercises in system and performance analysis and data collection and interpretation. The Stirling engine provides a context where learning is exciting and students explore the effects of design and fabrication changes. It also serves as a framework to discuss fundamental engineering topics including thermodynamics, mechanics of materials, material selection, machine dynamics, vibrations, and surface finish.

\section{Acknowledgements}

We would like to thank MIT for beginning this project and their publication of it in Mechanical Engineering Design. Furthermore, we acknowledge their prompt and courteous response to our request for plans and vendor addresses. Their large number of student websites provide an excellent overview of the Stirling Engine project. 


\section{References}

1. Otto, Kevin N. and Wood, Kristin L. "Designing the Design Course Sequence." Mechanical Engineering Design November 1999: 39 - 42.

2. MIT student web pages may be found at: http://me.mit.edu/2.670/.

3. Gould, Marty. Zen Machine \& Scientific Instrument, 1568 Steamboat Valley Rd. P.O. Box 1658, Lyons, CO 80540. Tel: (303) 823-5842.

4. Den Hartog, J. P. Mechanics. New York: Dover Publications, Inc., 1948.

\section{NATHANIEL B. ALLEN}

Nathaniel Allen is a Masters degree candidate at the University of Idaho. He earned his B.S.M.E. at the University of Idaho in 2000. His professional interests include manufacturing and materials handling / processing. He is a member of the Idaho Engineering Works and the Society of Manufacturing Engineers.

\section{J. MATTHEW CUNNINGTON}

Matthew Cunnington is a Masters degree candidate at the University of Idaho. He received his B.S.M.E. from the University of Idaho in 2000. His research includes design of a user-friendly wind tunnel facility for teaching design to beginning engineering students.

\section{LEVI J. WESTRA}

Levi Westra is a Masters degree candidate at the University of Idaho. He received his B.S.M.E. from the University of Idaho in 2000. His research interests include engineering teaching methods and focus on design-build-test projects. He is a member of the Idaho Engineering Works and enjoys mentoring Capstone Senior Design.

\section{MICHAEL K. KLEIN}

Michael Klein is a Masters degree candidate at the University of Idaho. He received his B.S.M.E. from the University of Idaho in 2001. During his undergraduate work, he performed combustion research for the Center for Clean Vehicle Technology at the University of Idaho. His research includes the establishment of a radioisotope laboratory for the purpose of detecting microscopic leaks from small cavities.

\section{DR. EDWIN M. ODOM}

Dr. Edwin Odom has taken an active interest in the ME Machine Shop as a key element in design education since joining the University of Idaho eleven years ago. Dr. Odom maintains an avid interest in the literature of creativity and management and is especially well versed on the subjects of team dynamics and leadership styles. He was recognized for his role in development of the Idaho Engineering Works by a university teaching award in 1998 .

\section{DR. RONALD E. SMELSER}

Dr. Ronald E. Smelser is a Professor of Mechanical Engineering at the University of Idaho. He holds degrees from the University of Cincinnati, MIT, and Carnegie Mellon University. Prior to joining the University of Idaho, he worked for fourteen years at U. S. Steel, Alcoa, and Concurrent Technology Corporation. He currently teaches the mechanics, materials, and Sophomore Laboratory courses and is involved with the Idaho Engineering Works. 